\title{
Clinical significance of side population in ovarian cancer cells
}

\author{
Shinji Hosonuma • Yoichi Kobayashi • \\ Satoshi Kojo • Haruka Wada $\cdot$ Ken-ichiro Seino • \\ Kazushige Kiguchi $\cdot$ Bunpei Ishizuka
}

Received: 11 October 2010/Accepted: 16 October 2010/Published online: 7 January 2011

(C) The Author(s) 2010. This article is published with open access at Springerlink.com

\begin{abstract}
Recently, accumulating evidence has suggested that tumors, including ovarian cancer, are composed of a heterogeneous cell population with a small subset of cancer stem cells (CSCs) that sustain tumor formation and growth. The emergence of drug resistance is one of the most difficult problems in the treatment of ovarian cancer, which has been explained recently by the potential of CSCs to have superior resistance against anti-cancer drugs than conventional cancer cells. In this study, we expanded this line of study to examine whether this phenomenon is also observed in clinical specimens of ovarian cancer cells. In total we could analyze 28 samples out of 60 obtained from ovarian cancer patients. The clinical samples were subjected to testing of the expression of side population (SP) as a CSC marker, and according to the presence of SP $(\mathrm{SP}+)$ or absence of $\mathrm{SP}(\mathrm{SP}-)$, clinicopathological significances were analyzed. Although there was no statistical significance, there were more $\mathrm{SP}+\mathrm{s}$ in recurrent cases as well as in ascitic and peritoneal dissemination than in primary tumor of the ovary. There was no correlation
\end{abstract}

\footnotetext{
S. Hosonuma · Y. Kobayashi $\cdot$ K. Kiguchi $(\bowtie) \cdot$ B. Ishizuka Department of Obstetrics and Gynecology,

St. Marianna University School of Medicine,

2-16-1 Sugao, Miyamae-ku, Kawasaki,

Kanagawa 216-8511, Japan

e-mail: kkiguchi@marianna-u.ac.jp

S. Kojo $\cdot$ H. Wada $\cdot$ K. Seino

Institute of Medical Science, St. Marianna University

School of Medicine, 2-16-1 Sugao, Miyamae-ku,

Kawasaki, Kanagawa 216-8511, Japan

Y. Kobayashi

Department of Obstetrics and Gynecology,

Kyorin University School of Medicine,

6-20-2 Shinkawa, Mitaka, Tokyo 181-8611, Japan
}

between SP status and FIGO staging. In 19 cases of those who could be followed more than 6 months from initial therapy, there were 8 cases of recurrence or death from disease, and all of these were SP+. On the other hand, in 11 cases of disease-free survivors, 6 were $\mathrm{SP}+$. There was a significant difference in prognosis between $\mathrm{SP}+$ and $\mathrm{SP}-$ $(p=0.017)$. Although this study was limited, it revealed that SP could be contained more in recurrent or metastatic tumors than in primary tumors, and also that the presence of SP could be a risk factor of recurrence in ovarian cancer. Therefore, a novel therapeutic strategy targeting SP could improve the prognosis of ovarian cancer.

Keywords Ovarian cancer - Side population (SP) . Cancer stem cells (CSCs) · Prognosis

\section{Introduction}

Ovarian cancer is the most lethal gynecological malignancy. The number of ovarian cancer patients is gradually increasing in Japan, as well as in the United States and European countries. In 2008, 4,599 patients died of ovarian cancer, making it the tenth most fatal malignancy in Japan. Usually ovarian cancer patients lack symptoms because the ovaries reside within the pelvic cavity, and effective screening methods have not yet been developed. As a result, more than half of the ovarian cancer patients are stage III or IV at the time of diagnosis. Although taxanes improve 5year survival in advanced ovarian cancer [1], many patients experience recurrence because of resistance to anti-cancer drugs. Therefore, novel therapeutic strategies are needed.

Recently, accumulating evidence has suggested that tumors, including ovarian cancer, are composed of a heterogeneous cell population with a small subset of cancer 
stem cells (CSCs) that sustain tumor formation and growth. The emergence of drug resistance is one of the most difficult problems in the treatment of ovarian cancer, but has recently been explained by the discovery that CSCs have resistance against anti-cancer drugs that is superior to that of conventional cancer cells. Therefore, clarifying the mechanism of CSC drug resistance could result in the development of novel therapeutic strategies.

Several reports have shown that CSCs are enriched in a side population (SP) that is recognized by fluorescenceactivated cell sorting (FACS) [2-4]. To date, SP has been detected in various solid tumor cells, such as breast [5], colon [6, 7] and pancreatic cancer [8], as well as ovarian cancer [9-11]. We also found that SP is significantly increased in chemoresistant ovarian cancer cell lines (in submission). However, the significance of SP in clinical samples, such as cancer tissue or cancer cells in ascitic fluid, still remains unclear [12, 13]. Therefore, we conducted a clinical study to clarify the significance of SP in clinical samples.

\section{Materials and methods}

\section{Clinical samples}

Clinical samples, such as cancer tissue or cancer cells in ascitic fluid, were obtained from patients with ovarian, peritoneal or tubal cancer from January 2009 to July 2010 at St. Marianna University Hospital. Informed consent was obtained from all patients, and this study was approved by the internal review board of our institution. Tissues or ascites harvested during laparotomy or by ultrasound-guided puncture were centrifuged to isolate the cellular component and then resuspended in HAM-12 containing antibiotics.

Analysis of the side population in human ovarian cancer tissues and ascites by flow cytometry

Human ovarian cancer tissues were washed with phosphatebuffered saline (PBS) and then cut into 1-mm-diameter pieces. These pieces were then transferred into PBS containing $2.4 \mathrm{U} / \mathrm{ml}$ of DISPASE ${ }^{\circledR}$ (GIBCO) and incubated for $60 \mathrm{~min}$ at $37^{\circ} \mathrm{C}$. After passing through a Cell Strainer ${ }^{\mathrm{TM}}$ with 70- $\mu \mathrm{m}$ pore size (BD Falcon), red blood cells were lysed using PharmLyse ${ }^{\mathrm{TM}}$ (BD Bioscience), and the resulting single-cell suspension was diluted to $1.0 \times 10^{6}$ cells $/ \mathrm{ml}$. For the staining of the SP, cells were pre-incubated for $10 \mathrm{~min}$ at $37^{\circ} \mathrm{C}$ and then incubated for an additional $80 \mathrm{~min}$ at $37^{\circ} \mathrm{C}$ with $5 \mathrm{mg} / \mathrm{ml}$ Hoechst 33342 (Sigma-Aldrich, Japan). SP cells were determined by the exclusion of Hoechst 33342, which was inhibited by verapamil (SigmaAldrich, Japan). Verapamil was added after pre-incubation at the start of the Hoechst 33342 staining at a final concentration of $50 \mu \mathrm{M}$. Live cells were gated based on forward and side scatter as well as lack of propidium iodide uptake. Flow cytometry was performed using a J-SAN ${ }^{\circledR}$ (Bay Bioscience, Japan) instrument and analyzed by FlowJo ${ }^{\circledR}$ software (TOMY Digital Biology Co. Ltd., Japan). Tissues/cells that satisfied the following conditions were defined as tissues/ cells containing SP: (1) the percentage of cells in the SP fraction was $>0.15 \%$, and (2) after verapamil administration, more than half of the cells were diminished from the SP fraction. Mann-Whitney $U$ test or Fisher's exact probability test were used to determine statistical significance, and $p<0.05$ was considered significant.

\section{Results}

Clinical samples were obtained from a total of 60 patients. Six cases were not primary ovarian cancer and were excluded from this study. Among the remaining 54 samples, 26 could not be analyzed because they contained too much debris, were contaminated with normal tissues or were too small to be analyzed. In the 28 samples that were evaluable for the study, the patient age ranged from 20 to 73 years old. Patient characteristics are shown in Table 1.

Of 28 samples, 18 contained an SP (SP+) and 10 did not $(\mathrm{SP}-)$. Figure 1 shows the FACS analysis for a $\mathrm{SP}+$ sample. The mean ages of $\mathrm{SP}+$ and $\mathrm{SP}-$ patients were 52.6 and 49.2 years old, respectively; however, they were not significantly different. Of 24 patients with samples obtained at primary surgery or neoadjuvant chemotherapy (NAC), 15 were $\mathrm{SP}+(62.5 \%)$. Of four recurrent cases, three were $\mathrm{SP}+(75 \%)$. Although the difference between primary and recurrent cases was not significant $(p=0.55)$, more recurrent cases were $\mathrm{SP}+$.

Of 18 samples obtained directly from ovarian tumors, 10 were $\mathrm{SP}+(55.6 \%)$. However, of eight ascitic fluid and two peritoneal dissemination samples, six $(75 \%)$ and two $(100 \%)$ were $\mathrm{SP}+$, respectively. Although the difference was not significant, there were more $\mathrm{SP}+$ samples in ascitic fluid and peritoneal dissemination than in primary ovarian tumors.

Focusing on the histology, there were eight cases of endometrioid carcinoma ( $\mathrm{SP}+: 5$ vs. $\mathrm{SP}-: 3$ ), seven cases of serous carcinoma (4 vs. 3) and five cases of clear cell carcinoma (3 vs. 2), with no correlation between $\mathrm{SP}+$ and histology. According to FIGO staging, there were 11 cases of stage I/II and 17 cases of stage III/IV. Of the stage I/II cases, 5 were $\mathrm{SP}+(45.4 \%)$, while 13 of the stage III/IV cases were $\mathrm{SP}+(76.5 \%)$. There was no correlation between $\mathrm{SP}+$ and FIGO staging $(p=0.22)$.

In the 19 patients that could be followed more than 6 months from the initial therapy, there were 8 cases of recurrent or fatal disease, and all 8 were $\mathrm{SP}+$. However, in 
Table 1 Patient characteristics that could be analyzed by FACS

\begin{tabular}{|c|c|c|c|c|c|}
\hline Age & Background & Pathology & FIGO & Sample & Prognosis \\
\hline \multicolumn{6}{|c|}{$\mathrm{SP}+$ group } \\
\hline 37 & 0 & Endometrioid & Ic & $\mathrm{T}$ & $\mathrm{a}$ \\
\hline 38 & 0 & Endometrioid & IIIIa & $\mathrm{T}$ & DFS \\
\hline 38 & 0 & LPM, serous & Ic & $\mathrm{T}$ & $\mathrm{a}$ \\
\hline 41 & 0 & Endometrioid & IIIc & A & $\mathrm{a}$ \\
\hline 42 & 0 & Serous & IIII & $\mathrm{T}$ & DOD \\
\hline 43 & 0 & Clear & IIII & $\mathrm{T}$ & DOD \\
\hline 43 & 1 & Clear & IIII & A & DOD \\
\hline 48 & 0 & Serous & IIIc & $\mathrm{T}$ & $\mathrm{a}$ \\
\hline 48 & 0 & Endometrioid & Ic & $\mathrm{T}$ & DFS \\
\hline 56 & 0 & Mucinous & IIIc & $\mathrm{T}$ & AWD \\
\hline 56 & 0 & Clear & IIIc & $\mathrm{T}$ & DFS \\
\hline 60 & 0 & Mucinous & IIIIc & A & DOD \\
\hline 61 & 1 & Serous & IIIC & $\mathrm{P}$ & AWD \\
\hline 62 & 0 & Adenocarcinoma $^{\mathrm{b}}$ & Ia & $\mathrm{A}$ & DFS \\
\hline 64 & 0 & Serous & IIIc & $\mathrm{P}$ & DOD \\
\hline 67 & 1 & SSPC & IIIc & A & DOD \\
\hline 69 & 0 & Adenocarcinoma $^{c}$ & IIIc & $\mathrm{A}$ & $\mathrm{a}$ \\
\hline 73 & 0 & Endometrioid & Ic & $\mathrm{T}$ & DFS \\
\hline \multicolumn{6}{|c|}{$\mathrm{SP}-$ group } \\
\hline 20 & 0 & Dysgerminoma & Ia & $\mathrm{T}$ & $\mathrm{a}$ \\
\hline 20 & 0 & LPM, mucinous & Ic & A & $\mathrm{a}$ \\
\hline 40 & 1 & Endometrioid & IV & $\mathrm{T}$ & DFS \\
\hline 41 & 0 & Endometrioid & IIIc & $\mathrm{T}$ & $\mathrm{a}$ \\
\hline 46 & 0 & Endometrioid & Ic & $\mathrm{T}$ & DFS \\
\hline 60 & 0 & Clear & Ic & $\mathrm{T}$ & DFS \\
\hline 61 & 0 & Serous & IIIc & $\mathrm{T}$ & DFS \\
\hline 67 & 0 & Serous & Ic & $\mathrm{T}$ & DFS \\
\hline 68 & 0 & Serous & IIIC & A & $\mathrm{a}$ \\
\hline 69 & 0 & Clear & IIc & $\mathrm{T}$ & DFS \\
\hline
\end{tabular}

Background: 0: obtained from primary surgery; 1: recurrent case Sample: $T$ ovarian tumor, $A$ ascites, $P$ peritoneal dissemination $D F S$ disease-free survival, $A W D$ alive with disease, $D O D$ died of disease

${ }^{\text {a }}$ Follow-up period $<6$ months

b Histological diagnosis could not be made due to chemotherapeutic effect

${ }^{c}$ Laparotomy was not done, and histological diagnosis was made only by cytology of ascitic fluid

11 cases of disease-free survivors, 6 were $\mathrm{SP}+$, and 5 were $\mathrm{SP}-$. $\mathrm{SP}+$ was significantly correlated with a worse prognosis than $\mathrm{SP}-(p=0.017$, Fig. 2$)$. Of the $\mathrm{SP}+$ cases that were histologically designated as serous and mucinous carcinoma, all were recurrent or the patient died of disease. Of the SP+ clear cell carcinomas, two out of three cases recurred or the patient died of disease. However, there was no recurrent case in three $\mathrm{SP}+$ endometrioid carcinoma cases.

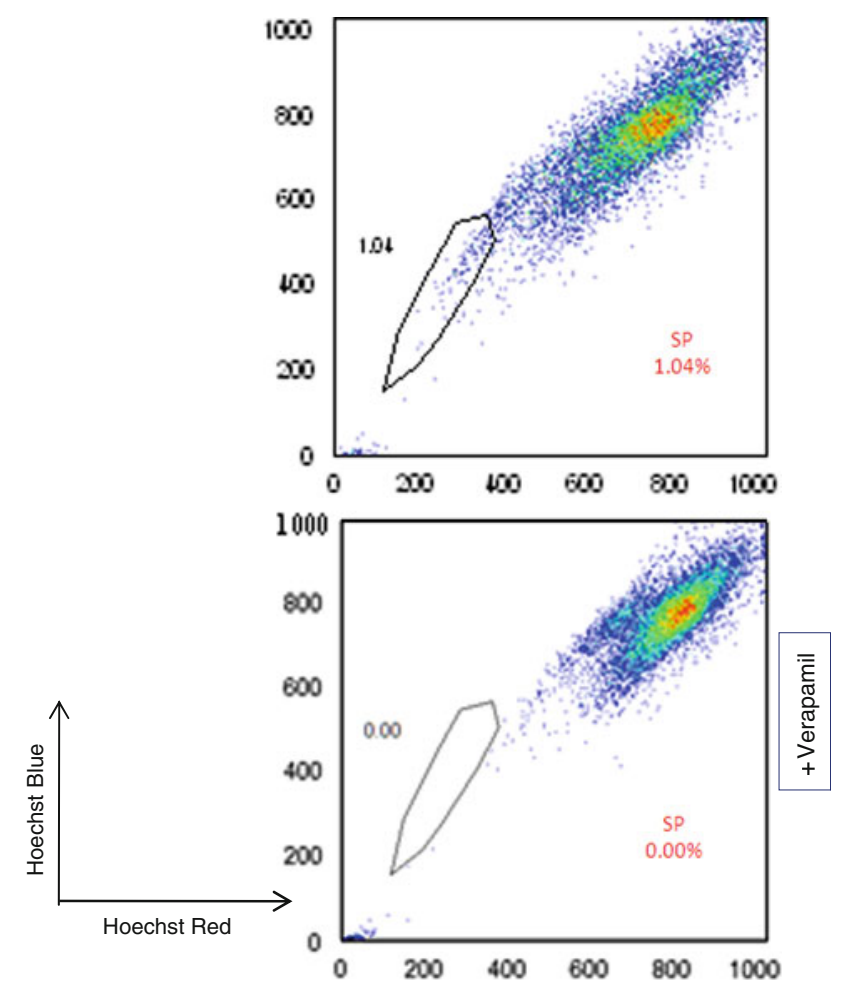

Fig. 1 An example of a patient determined as SP+ by flow cytometric analysis. After administration of verapamil, cells of the SP fraction were diminished. Vertical axis intensity of Hoechst blue, horizontal axis intensity of Hoechst red

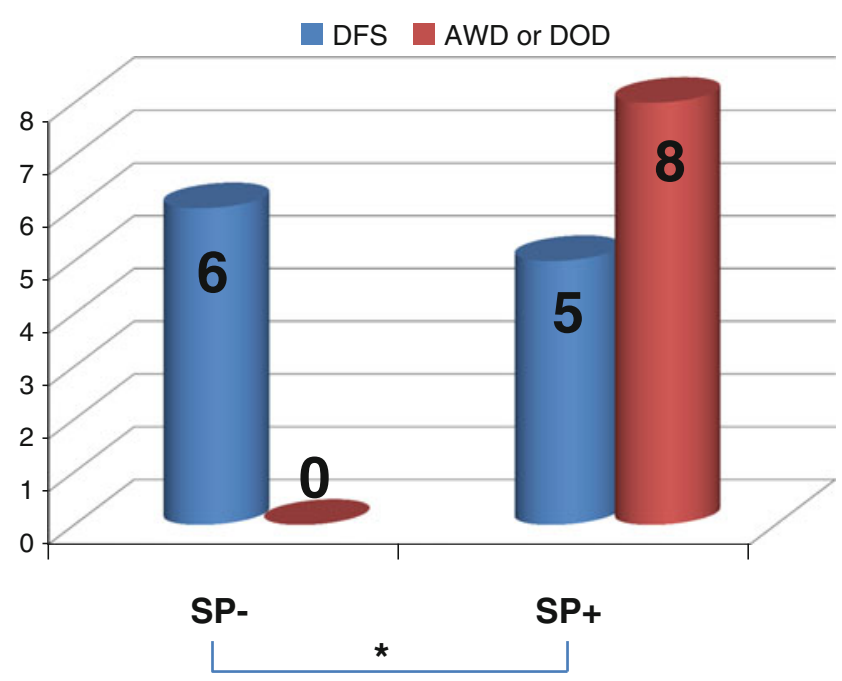

Fig. 2 Prognosis of the patients according to the presence or absence of SP. *There was statistical significance in the prognosis between $\mathrm{SP}+$ and $\mathrm{SP}-(p=0.017)$. Vertical axis number of cases. DFS disease-free survival, $A W D$ alive with disease, $D O D$ died of disease

\section{Discussion}

Several groups have reported about SP in ovarian cancer. Szotek et al. detected SP in human ovarian cancer cell lines 
as well as in primary ascites cancer cells. Moreover, SP cells in ovarian cancer were reported to have CSCs characteristics, suggesting that CSCs are also enriched in SP in ovarian cancer $[9,14]$. In our clinical study, the presence of SP was assessed in clinical tissues/cells in ovarian, peritoneal and tubal carcinoma patients. A total of 54 cases were analyzed, but the percentage of evaluable cases was only $51.9 \%$ (28/ $54)$. The evaluable rate was relatively low because cancer tissues in vivo could contain some amount of normal cells, mucous and cell debris. Moreover, cancer tissues could contain various polyclonal cancer cells. These factors might have interfered with analysis by FACS in our study. For this reason, novel procedures that could extract only cancer cells from clinical samples should be developed.

Once ovarian cancer develops, the tumor surface ruptures, and tumor cells are disseminated into the peritoneal cavity. Most ovarian cancers will spread by this process. CSCs were reported to be related to metastasis [15-17], which, if true, suggests that peritoneal dissemination could be promoted by CSCs. In the present study, although it was not statistically significant, $\mathrm{SP}+$ cases were detected more frequently in ascitic fluid or peritoneal dissemination than in primary tumors $(75,100$ vs. $55.6 \%)$. This result suggests that peritoneal dissemination in ovarian cancer is correlated with SP, which is supported by the fact that SP+ cases were detected more frequently in FIGO stage III/IV patients than in stage I/II (45.5 vs. $76.5 \%$ ). Stage III/IV patients already have peritoneal dissemination and/or distant metastasis, so it might be reasonable that SP could be detected in tissues from stage III/IV patients.

Although the histological difference was not correlated to the presence or absence of SP, in serous, mucinous and clear cell carcinoma patients that were $\mathrm{SP}+$, most experienced recurrence or died of disease. However, SP+ endometrioid carcinoma patients did not experience recurrence. Although the follow-up term was too short and the number of patients too small to reach a conclusion, in endometrioid carcinoma, the prognosis might not be affected by the presence of SP.

In the present study, all eight $\mathrm{SP}+$ patients experienced recurrence or died of disease within 2 years from initial therapy, suggesting that SP might be correlated with the risk of recurrence or death from disease. Some of these patients were resistant to the initial chemotherapy, which may indicate that SP containing rich CSCs is correlated to chemoresistance. Therefore, although the number of the studied cases was small, it indicates that detecting SP could predict the chemoresistance or prognosis of ovarian cancer.

In conclusion, our study suggests that SP might be correlated to peritoneal dissemination, and might also predict chemoresistance or prognosis in ovarian cancer. Because our study consisted of a small number of patients, a larger study should be conducted in order to define the clinical significance of SP in ovarian cancer. The technical difficulties of treating clinical samples for detecting SP/ CSCs should also be overcome.

Acknowledgments We are grateful to Hajime Kamijuku, Naoki Okamoto and Kaori Aida for their technical assistance.

Open Access This article is distributed under the terms of the Creative Commons Attribution Noncommercial License which permits any noncommercial use, distribution, and reproduction in any medium, provided the original author(s) and source are credited.

\section{References}

1. Lambrou N, Trimble EL. Dose-intensive approaches to ovarian cancer. Curr Oncol Rep. 1999;1:54-8.

2. Wulf GG, Wang RY, Kuehnle I, et al. A leukemic stem cell with intrinsic drug efflux capacity in acute myeloid leukemia. Blood. 2001;98:1166-73.

3. Hadnagy A, Gaboury L, Beaulieu R, et al. SP analysis may be used to identify cancer stem cell populations. Exp Cell Res. 2006;312:3701-10.

4. Wu C, Alman BA. Side population cells in human cancers. Cancer Lett. 2008;268:1-9.

5. Al-Hajj M, Wicha MS, Benito-Hernandez A, et al. Prospective identification of tumorigenic breast cancer cells. Proc Natl Acad Sci USA. 2003;100:3983-8.

6. Ricci-Vitiani L, Lombardi DG, Pilozzi E, et al. Identification and expansion of human colon-cancer-initiating cells. Nature. 2007;445:111-5.

7. Cui L, Ohuchida K, Mizumoto K, et al. Prospectively isolated cancer-associated CD10 fibroblasts have stronger interactions with CD133 colon cancer cells than with CD133 cancer cells. PLoS One. 2010;5:e12121.

8. Li C, Heidt DG, Dalerba P, et al. Identification of pancreatic cancer stem cells. Cancer Res. 2007;67:1030-7.

9. Szotek PP, Pieretti-Vanmarcke R, Masiakos PT, et al. Ovarian cancer side population defines cells with stem cell-like characteristics and Mullerian Inhibiting Substance responsiveness. Proc Natl Acad Sci USA. 2006;103:11154-9.

10. Bapat SA, Mali AM, Koppikar CB, et al. Stem and progenitorlike cells contribute to the aggressive behavior of human epithelial ovarian cancer. Cancer Res. 2005;65:3025-9.

11. Challen GA, Little MH. A side order of stem cells: the SP phenotype. Stem Cells. 2006;24:3-12.

12. Hirschmann-Jax C, Foster AE, Wulf GG, et al. A distinct "side population" of cells with high drug efflux capacity in human tumor cells. Proc Natl Acad Sci USA. 2004;101:14228-33.

13. Pan Y, Huang X. Epithelial ovarian cancer stem cells-a review. Int J Clin Exp Med. 2008;1:260-6.

14. Hu L, McArthur C, Jaffe RB. Ovarian cancer stem-like sidepopulation cells are tumourigenic, chemoresistant. Br J Cancer. 2010;102:1276-83.

15. Alvero $\mathrm{AB}, \mathrm{Fu} \mathrm{HH}$, Holmberg J, et al. Stem-like ovarian cancer cells can serve as tumor vascular progenitors. Stem Cells. 2009;27:2405-13.

16. Fong MY, Kakar SS. The role of cancer stem cells, the side population in epithelial ovarian cancer. Histol Histopathol. 2010;25:113-20.

17. Takaishi K, Komohara Y, Tashiro H, et al. Involvement of M2polarized macrophages in the ascites from advanced epithelial ovarian carcinoma in tumor progression via Stat3 activation. Cancer Sci. 2010;101:2128-36. 